\title{
A Study of 89 Cases of Oral Squamous Cell Carcinoma Presenting at Teaching Hospitals of Lahore, Pakistan
}

\author{
Rakia Sahaf ${ }^{1}$ \\ Nadia Naseem ${ }^{2}$ \\ Aman-ur-Rehman ${ }^{3}$ \\ Rabia Anjum ${ }^{4}$ \\ Abdul Hanan Nagi ${ }^{5}$
}

\author{
BDS, MPhil \\ MBBS, PhD \\ MBBS, FCPS \\ BDS, MPhil \\ MB PhD, FCPS, FCPP, FRC Path
}

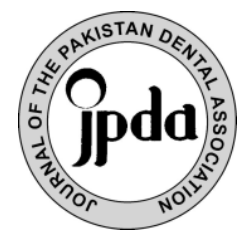

\begin{abstract}
:
OBJECTIVE: Oral squamous cell carcinoma (OSCC) is one of the most prevalent malignant neoplasm in south Asia and a major public health problem in Pakistan due to its high morbidity and poor survival rates. The objective of the study was to describe the clinical pattern of oral squamous cell carcinoma in tertiary care hospitals of Lahore.

METHODOLOGY: A cross sectional study was done at tertiary care hospitals of Lahore where demographic and clinical data of eighty nine histologically diagnosed cases of OSCC was studied.

RESULTS: Mean age of the patients was $53.13 \pm 14.82$ years and male to female ratio was $1.4: 1$ with $58.4 \%$ males and $41.6 \%$ females. Tongue was the most frequently affected site $37.1 \%$ followed by buccal mucosa $30.3 \%$. The most common presenting complaint was non healing ulcer 50.6\%.Mean duration of lesions at presentation was $5 \pm 3.68$ months. 66.3\% cases reported with history of smoking, chewing tobacco/snuff and betel quid. Smoking was the most prevalent etiological agent accounting for $22.5 \%$ cases and was found to be significantly higher in the male population $(\mathrm{p}<0.001)$.
\end{abstract}

CONCLUSIONS: Most cases of oral squamous cell carcinoma (OSCC) in major hospitals of Lahore, Pakistan are reported in 5th to $6^{\text {th }}$ decade of life, with male preponderance. Ulceration is the most common clinical manifestation in OSCC patients with about two-third cases reporting within 6 months of onset of lesions. Tongue is the most commonly affected site and smoking tobacco and betel quid chewing are the main risk factors implicated in OSCC.

KEYWORDS: Oral Squamous Cell Carcinoma; oral cancer; risk factors; smoking

HOW TO CITE: Sahaf R, Naseem N, Rehman A, Anjum R, Nagi AH. A Study of 89 Cases of Oral Squamous Cell Carcinoma Presenting at Teaching Hospitals of Lahore, Pakistan. J Pak Dent Assoc 2017; 26(1): 26-31

Received: 11 November 2016, Accepted: 15 February 2017

\section{INTRODUCTION}

$\mathrm{O}$ ral cancer is a potentially fatal disease with continuing increase in worldwide incidence and constantly poor survival rates. ${ }^{1}$ Oral squamous cell carcinomas (OSCC) is one of the most frequent globally reported malignant neoplasm, accounting for $>90 \%$ of oral cancers. It arises from the mucous membrane of the oral cavity and may affect any anatomical site in the oral cavity including lips, retromolar area, buccal and labial mucosa, gingiva, palate and the floor of the mouth.

1,2,4,5 Department of Oral Pathology, University of Health Sciences Lahore ${ }^{3}$ Department of Histopathology, Sheikh Zayed Hospital Lahore, Pakistan Corresponding author: "Dr. Rakia Sahaf"

< rakiasahaf@gmail.com >
Globally, there is a marked variation in geographical distribution and incidence of oral cancer. The geographic incidence of 3-6\% and 30\% is seen in the Western and Eastern countries respectively. ${ }^{2}$ In Pakistan, it is the second most common malignancy ${ }^{3}$ and constitutes $15 \%$ of estimated new cancer cases compared to $3 \%$ found worldwide. ${ }^{4}$ The risk of developing OSCC rises with age and most of the cases occur after the fifth decade of life in the Asian populations. Globally, the incidence and mortality rates of oral cancer are higher for men than women due to greater indulgence in high risk habits by males as compared to the females. ${ }^{4}$ In developing countries like Pakistan, greater prevalence of use of tobacco, areca nut and betel quid is known as a strong risk factor for developing oral cancers and oral potentially malignant disorders. ${ }^{5}$ 
OSCC is manifested in various clinical forms. It may present as leukoplakia (white plaque), verrucous leukoplakia, erythroplakia (red lesion) or erythroleukoplakia. With time, it may eventually develop into an ulcer with irregular, indurated and rolled border or as an exophytic broad-based mass or a fungating mass with the invasion of local structures. ${ }^{6}$ OSCC may also present as a lump, as a non-healing extraction socket or as a cervical lymphadenopathy, characterized by hardness or fixation. ${ }^{7}$

Mortality and morbidity of OSCC has not changed considerably over the last few decades due to its high degree of local invasiveness and a high rate of metastasis. ${ }^{8}$ The 5year survival rate is only $50 \%{ }^{9}$ with maximum patients usually dying within the first 2-3 years of illness. ${ }^{10}$ Thus, there is a great need to establish novel, effective and less toxic therapeutic alternatives to standard therapy in order to improve the prognosis for patients with oral cancer. The present study was carried out to describe the clinical pattern of oral squamous cell carcinoma presenting at tertiary care hospitals of Lahore.

\section{METHODOLOGY}

A cross sectional study was conducted from January 2010 to September 2015 in Lahore, Pakistan. Demographic and clinical data of eighty nine cases were collected through the departmental records of Mayo hospital, Sheikh Zaid Hospital and AllamaIqbal Medical College/ Jinnah Hospital, Lahore. Histopathology was done at Department of Morbid Anatomy and Histopathology/Oral Pathology, University of Health Sciences, Lahore. The data was analyzed using SPSS 21.0. Pearson Chi square / Fisher Exact test were applied to determine associations between the variables including age, gender, site of involvement, clinical presentation, etiological agent and the duration of OSCC lesion. A p value of $\leq 0.05$ was considered as statistically significant. This study was approved by the institutional ethical review committee and also from Advanced Studies and Research Board of University of Health Sciences Lahore, Pakistan (ERC approval vide letter no: UHS/Education/126-15/1776)

\section{RESULTS}

The overall mean age of the study population was 53.13 \pm 14.82 years with the age range of $25-80$ years. The male to female ratio was $1.4: 1$ with $52(58.4 \%)$ males and $37(41.6 \%)$ females. Most cases reported in 5 th to $6^{\text {th }}$ decade of life with male predominance $(\mathrm{p}<0.001)$ (Fig. 1).

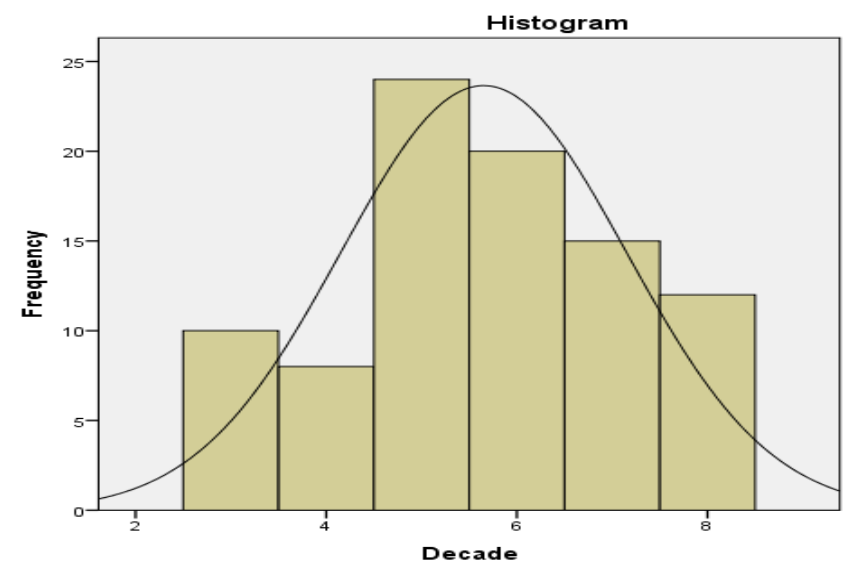

Fig. (1). Age distribution of OSCC cases.

Regarding the site of involvement of oral cavity, occurrence of OSCC was found considerably higher on the tongue followed by buccal mucosa and other sites (Table 1). In males, predominant involvement of buccal mucosa was seen $17(32.7 \%)$ whereas in females, tongue involvement was higher $18(48.6 \%)$.

Diverse clinical presentations were recorded among study patients (Fig. 2) with most of the casespresenting withnon-healing ulcer (Table 1). The presence of ulcer was found to be significantly higher on the tongue $(\mathrm{P}<0.001)$.

The duration of lesions in the study cases varied between 0-6 months in 61(68.5\%) cases, 7-12 months in 22(24.7\%), and $>12$ months in $6(6.7 \%)$ cases.Mean duration of lesions at presentation was $5 \pm 3.68$ months (ranging from 1 month to 19 months). Mean duration was longer for males (5.17 \pm 3.81 , ranging from 1 to 19 months) than for females (4.76 \pm 3.53 , ranging from 1 to 18 months)Significant association was found between the duration of lesions and age $(\mathrm{p}<0.001)$ and site of involvement $(\mathrm{p}=0.01)$ of OSCC.

As regards the etiology, 59(66.3\%) cases reported with history of smoking, chewing tobacco/snuff and betel quid. While $30(33.7 \%)$ cases had no identifiable risk factors. Smoking was the most commonetiological agent in the current study accounting for $20(22.5 \%)$ cases and was found to be significantly higher among the male population $19(36.5 \%)$ while betel quid chewing was more common in females $10(27 \%)(\mathrm{p}<0.001)$.A significant association wasfound between the etiological agents and the site of involvement of the tumor $(\mathrm{p}<0.001)$. However, it was not possible to determinesmoking, betel quid and tobacco consumption in terms of frequency andduration of use. 
Table 1. Site Distribution with respect to Gender and Clinical Presentationof OSCC.

\begin{tabular}{|c|c|c|c|c|c|c|c|c|c|}
\hline \multirow[b]{2}{*}{ Site } & \multicolumn{2}{|c|}{ Gender } & \multirow[b]{2}{*}{$\begin{array}{c}\text { p- } \\
\text { value }\end{array}$} & \multicolumn{4}{|c|}{ Clinical Presentation } & \multirow[b]{2}{*}{$\begin{array}{l}\text { Total } \\
(\%)\end{array}$} & \multirow[b]{2}{*}{ p-value } \\
\hline & Female & Male & & Ulceration & $\begin{array}{l}\text { Lump/ } \\
\text { swelling }\end{array}$ & $\begin{array}{c}\text { Verrucous/ } \\
\text { exophytic } \\
\text { mass }\end{array}$ & $\begin{array}{l}\text { White patch } \\
\text { (leukoplakia) }\end{array}$ & & \\
\hline Buccal Mucosa & 10 & 17 & \multirow{8}{*}{0.286} & 13 & 6 & 5 & 3 & $27(30.3 \%)$ & \multirow{8}{*}{$<0.001$} \\
\hline Gingiva & 0 & 3 & & 1 & 2 & 0 & 0 & $3(3.4 \%)$ & \\
\hline Hard Palate & 1 & 1 & & 2 & 0 & 0 & 0 & $2(2.2 \%)$ & \\
\hline Lip & 4 & 9 & & 2 & 11 & 0 & 0 & $13(14.6 \%)$ & \\
\hline Retromolar area & 0 & 3 & & 0 & 1 & 2 & 0 & $3(3.4 \%)$ & \\
\hline Sub-mandibular gland & 4 & 4 & & 2 & 6 & 0 & 0 & $8(9 \%)$ & \\
\hline Tongue & 18 & 15 & & 25 & 2 & 2 & 4 & $33(37.1 \%)$ & \\
\hline Total & 37 & 52 & & 45 & 28 & 9 & 7 & $89(100 \%)$ & \\
\hline
\end{tabular}

Chi square/ Fisher Exact test was applied at 0.05 level of significance.

A
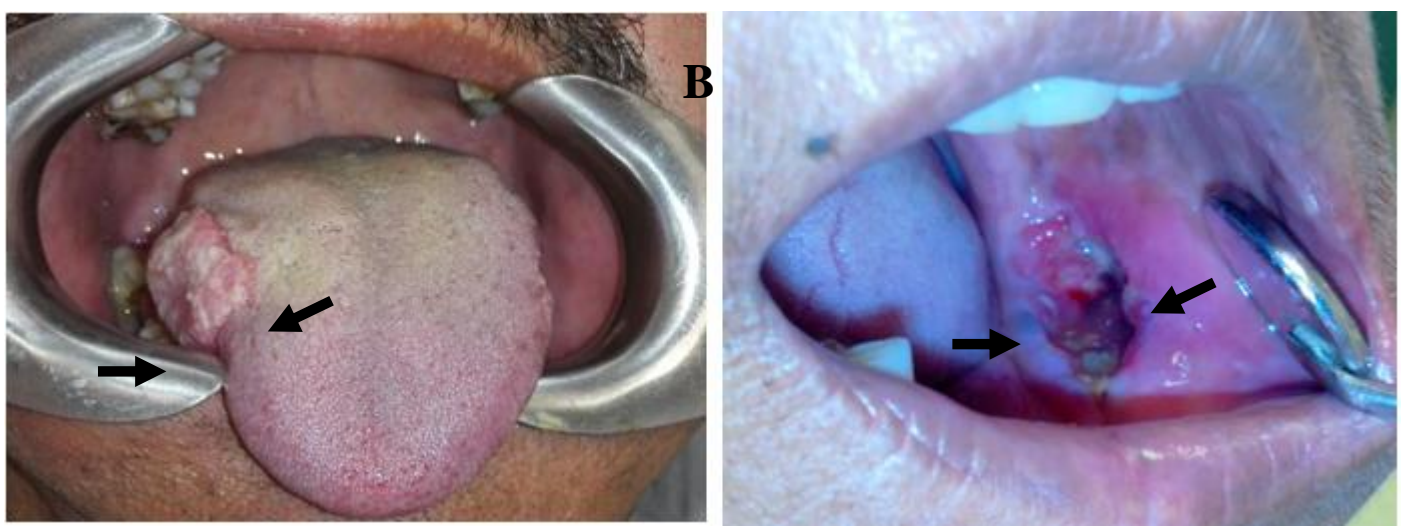

Fig. (2). (A) An exophytic lesion of OSCC on theright lateral border of tongue(B)An ulcerated lesion of OSCC on left buccal mucosa.

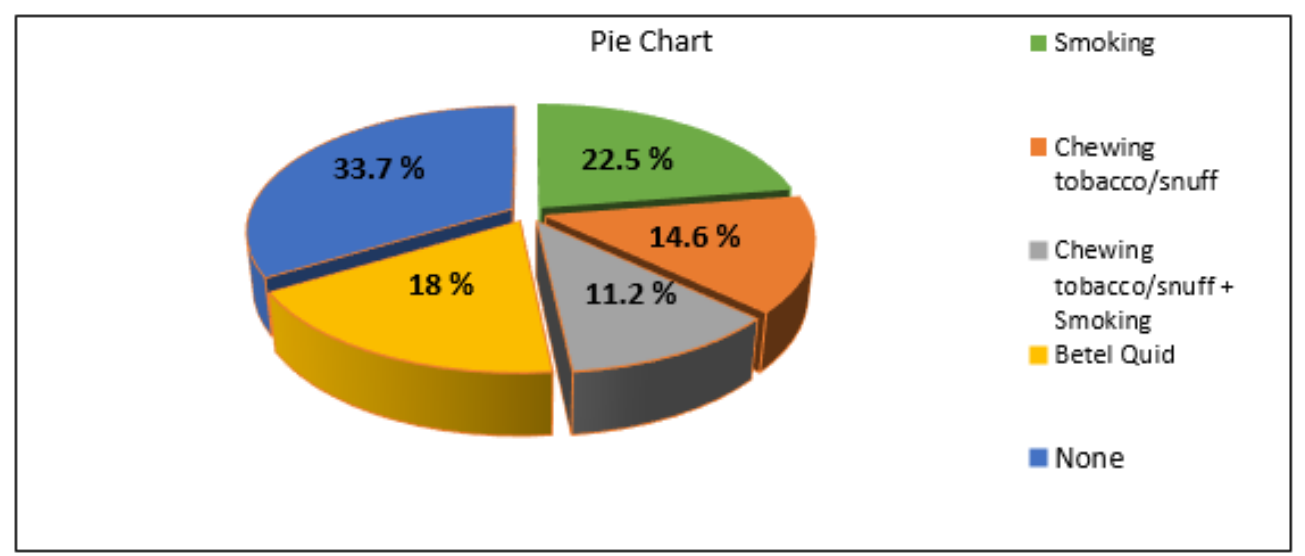

Fig. (3). Frequency of common etiological agents in OSCC patients. 


\section{DISCUSSION}

Incidence of oral squamous cell carcinomas (OSCCs) widely differs worldwide with the prevalence being highest in the Indo-Pak subcontinent. Identifying trends in the incidence rates of oral squamous cell carcinoma (OSCC) in relation to age, gender, site distribution and tumor stage are essential in making the therapeutic decisions. A total of 89 cases, histologically diagnosed as OSCC were recruited in the study. In the present study, the overall mean age at the time of presentation/ diagnosis of OSCC was $53.13 \pm 14.82$ years. The age range in males was 25 to 80 years while in females the age range was 25 to 75 years with most cases reported in 5 th to $6^{\text {th }}$ decade of life. These findings were consistent with the study done in Karachi ${ }^{11}$ demonstrating age of patients ranging from 25 to 80 years with most cases seen in the fifth decade. Similarly, a study conducted by Rahmanetal. ${ }^{12}$ reported $50.46 \pm 3.78$ years mean age which is similar to the present study. Contrarily, Alamgir et al. ${ }^{13}$ in

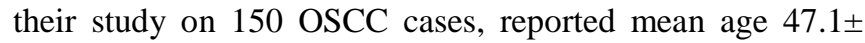
12.22 years.

The gender related findings of the present study showed male to female ratio $1.4: 1$, showing male predilection. This was consistent with the local $^{14}$ and international studies ${ }^{15}$ both of which showed definite male preponderance. The highest male predilection for OSCC was reported in Taiwan where male to female ratio of 10.5:1 was seen. ${ }^{16}$ In Pakistani society males are more exposed to risk factors such as tobacco, araeca nut and betel quid use compared to females, thus resulting in developing more OSCC.

As regards the site of OSCC, tongue was involved most frequently in the present study (37.1\%) followed by buccalmucosa (30.3\%). An epidemiological study of OSCC carried out in Mexico by Hernandez-Guerrero etal. ${ }^{15}$ reported tongue as the predominant site of involvement (44.7\%). Similar results demonstrated by Tahasetal. ${ }^{17}$ as well. On the contrary, Bhurgri ${ }^{18}$ in her report from South Karachi demonstrated that in oral malignancy, the buccal mucosa was most frequently involved (55.9\%), followed by tongue (28.4\%).The site predilection varied throughout the world. In Iraq, lip was preferential site in people exposed to ultraviolet radiation ${ }^{19}$ whereas in Hungary, floor of mouth was the most frequently affected sitein OSCC patients. ${ }^{20}$ The site variations could be attributed to the intensity of exposure to different risk factors prevalent worldwide. Moreover Subashrajet al. ${ }^{21}$ reported that the high risk relating these sites is due to saliva mixed with carcinogens constantly bathe these sites and the thinner, non-keratinized mucosa lining these sites offer decreased protection against carcinogens.

JPDA Vol. 26 No. 01 Jan-Mar 2017
In the present study, a slightly higher frequency of buccal mucosa tumors in males was seen whereas among females, tongue was predominantly involved. Contrarily, Kruse etal. ${ }^{22}$ showed that females were affected more by OSCC on the palate and maxillary alveolar ridge whereas among males, most common site was mandibular alveolar ridge. The reason for this differential site predilection for OSCC in both the genders is unknown.

Clinical aspect of the tumor revealed that ulceration was the most frequent manifestation seen in the present study $(50.6 \%)$ followed by swelling/lump, white patch (leukoplakia) and verrucous/ exophytic mass in descending order. Akin to the findings of the present study, studies carried out by Khaleeletal. ${ }^{14}$ demonstrated that ulceration was the most common presentation in OSCC patients. Whereas Falaki et al. ${ }^{23}$ observed exophytic lesion with ulcer as the most common clinical presentation in OSCC of young patients in Iran.

A significant association $(\mathrm{p}<0.001)$ was found between the site of involvement and the clinical presentation of the tumor in the present study showing that the lesions of tongue generally ulcerate. This finding was consistent with other observations. ${ }^{24}$

In the present study, the mean duration of the lesions at presentation was $5 \pm 3.68$ months which is somewhat similar to the study conducted in Kenya ${ }^{25}$ reporting a mean duration of 7.2 months.Consistent with the findings of Shenoiet $a l .{ }^{26}, 68.5 \%$ of patients reported within 6 months of onset of the lesions. Delayed presentation can be attributed to lack of awareness about the symptoms and misinterpretation of oral symptoms as minor oral conditions. ${ }^{27}$ Morelattoetal. $^{28}$ reported that, both patients and professionals were responsible for the delay in diagnosis and the treatment.

Consistent with the findings of Syamet al. ${ }^{29}$, smoking was the most prevalent etiological agent among the OSCC patients in the present study. Schmidtet al. ${ }^{30}$ stated that smoking is the most common form of tobacco consumption, accounting for $41 \%$ of OSCC cases with the smokers being 6-8 times more prone to develop OSCC compared to nonsmokers. In accordance with the present study, Akram etal. ${ }^{11}$ demonstrated that betel quid chewing was more common in females while tobacco smoking habit was prevalent among males. However Sharma etal. $^{31}$ reported that the consumption of smokeless tobacco was more common than smoking habits in both the genders.

The limitations of the present study are small and distinct sample population taken from particular hospital settings that subsequently restricts generalizability of findings of this study. Secondly, the clinical stage of squamous cell carcinoma in study patients is not described in the present 
study as a comprehensive and detailed data collection in this regards is underway for future research purpose.

\section{CONCLUSIONS}

In major hospitals of Lahore, Pakistan, most cases of oral squamous cell carcinoma (OSCC) are reported in 5th to $6^{\text {th }}$ decade of life, with male preponderance. Tongue is the most frequently affected site, followed by buccal mucosa. Ulceration is the most prevalent clinical presentation with majority of the patients reporting within 6 months of the onset of lesions.

\section{CONFLICT OF INTERET}

Authors declare NO conflict of interests.

\section{ACKNOWLEDGEMENT}

The authors acknowledge the encouragement extended by the Vice Chancellor of UHS, Lahore. Also the laboratory staff of Oral Pathology Dept. of UHS, Lahore for their technical and logistic support.

\section{CONTRIBUTION BY AUTHORS}

1 RakiaSahaf: Conception, synthesis and planning of the research interpretation, analysis and discussion.

2 Nadia Naseem: Conception and planning of the research interpretation.

3 RabiaAnjum: Active participation in methodology.

4. Aman-ur-Rehman: Active participation in methodology.

5. AH Nagi: Supervisor.

\section{REFERENCES}

1. Noguti J, De Moura CF, De Jesus GP, Da Silva VH, Hossaka TA, Oshima CT, et al. Metastasis from oral cancer: an overview. Cancer Genomics Proteomics.2012; 9:329-335.

2. Ascani G, Balercia P, Messi M, Lupi L, Goteri G, Filosa $\mathrm{A}$, et al. Angiogenesis in oral squamous cell carcinoma. Acta Otorhino laryngol Ital. 2005; 25:13-7.

3. Cancer Registry and Clinical Data ManagementShaukatKhanum Memorial Cancer Hospital and Research Center. Report based on cancer cases registered at SKMCH \& RC from Dec. 1994 - Dec. 2011 and in 2011. [Internet]. [cited 201410 July] Available from: http://www.shaukatkhanum.org.pk/ research/cancer-registry-and-clinical-data-management. html

4. Ferlay J, Shin HR, Bray F, Forman D, Mathers C, Parkin DM. Estimates of worldwide burden of cancer in 2008: GLOBOCAN 2008. Int J Cancer. 2010; 127: 2893-2917

5. Khan Z, Tonnies J, Muller S. Smokeless Tobacco and Oral Cancer in South Asia: A Systematic Review with Meta-Analysis. J Cancer Epidemiol. 2014; 2014:394696.

6. Johnson N, Franceschi S, Ferlay J, Ramadas K, Schmid S, MacDonald DG, et al. Tumours of the Oral Cavity and Oropharynx-Squamous Cell Carcinoma. In: Barnes L, Eveson JW, Reichart P, Sidransky D, editors. Pathology and Genetics of Head and Neck Tumours. Lyon, France: IARC Press; 2005. pp. 168-175.

7. Markopoulos AK. Current aspects on oral squamous cell carcinoma. Open Dent J. 2012;6:126-30.

8. Chandolia B, Basu SK, Kumar M. Can MMP-9 be a Prognosticator Marker for Oral Squamous Cell Carcinoma? J Clin Diagn Res.2016; 10: ZC09-ZC13.

9. Marsh D, Suchak K, Moutasim KA, Vallath S, Hopper C, Jerjes W, et al. Stromal features are predictive of disease mortality in oral cancer patients. J Pathol.2011; 223: 470-81.

10. Hill BT, Price LA. Lack of survival advantage in patients with advanced squamous cell carcinomas of the oral cavity receiving neo-adjuvant chemotherapy prior to local therapy, despite achieving an initial high clinical complete remission rate. Am J Clin Oncol.1994;17: 1-5.

11. Akram S, Mirza T, Mirza MA, Qureshi M. Emerging patterns in clinico-pathological spectrum of oral cancers. Pak J Med Sci. 2013; 29:783-787.

12. Rahman SS, Sarker MK, Khan MHA, Biswas SS, Saha MM. Clinical profile of oral squamous cell carcinoma patients attending a tertiary care hospital. Bang Med JKhulna.2014; 47: 3-6.

13. Alamgir MM, Jamal Q, Mirza T. Conventional clinical and prognostic variables in 150 oral squamous cell carcinoma cases from the indigenous population of Karachi. Pak J Med Sci. 2016; 32:672-676

14. Khaleel ME, Raza A, Ehsan A, Masood R, Javed M. Clinicopathological spectrum of oral squamous cellcarcinoma at a public sector health facility. Biomedica. 2015; 31: $21-6$

15. Hernández-Guerrero JC, Jacinto-Alemán LF, JiménezFarfán MD, Macario-Hernández A, Hernández-Flores F, Alcántara-Vázquez A. Prevalence trends of oral squamous cell carcinoma. Mexico City's General Hospital experience.Med Oral Patol Oral Cir Bucal. 2013; 18:e306-311

16. Chiang CT, Hwang YH, Su CC, Tsai KY, Lian I, Yuan TH.Elucidating the underlying causes of oral cancer 
through spatial clustering in high-risk areas of Taiwan with a distinct gender ratio of incidence. Geospat Health. 2010; 4: 230-242.

17. Tahas IA, Younis WH. Clinicopathological analysis of oral squamous cell carcinoma in Iraq during period (2001-2013). J Bagh Coll Dentistry.2015; 27:58-65.

18. Bhurgri Y. Cancer of the oral cavity - trends in Karachi South (1995-2002). Asian Pac J Cancer Prev.2005; 6:22-6.

19. Al-Rawi NH, Talabani NG. Squamous cell carcinoma of the oral cavity: a case series analysis of clinical presentation and histological grading of 1,425 cases from Iraq. Clin Oral Invest.2008; 12:15-8.

20. Nemes JA, Redl P, Boda R, Kiss C, Márton IJ. Oral cancer report from Northeastern Hungary. Pathol Oncol Res. 2008; 14:85-92.

21. Subashraj K, Orafi M, Nair KV, El-Gehani R, Elarbi M. Primary malignant tumors of orofacial region at Benghazi, Libya: a 17 years review. Cancer Epidemiol. 2009; 33:332-6

22. Kruse AL, Bredell M, Grätz KW. Oral cancer in men and women: are there differences? Oral Maxillofac Surg. 2011; 15:51-5.

23. Falaki F, Dalirsani Z, Pakfetrat A, Falaki A, Saghravanian N, Nosratzehi $\mathrm{T}$, et al. Clinical and Histopathological Analysis of Oral Squamous Cell Carcinoma of Young Patients in Mashhad, Iran: a Retrospective Study and Review of Literature. Med Oral Patol Oral Cir Bucal. 2011; 16: e473-7.
24. Sunil A, Kurien J, Mukunda A. Common Superficial Tongue Lesions. Ind J ClinPract.2013; 23: 534-42.

25. Muange P, Chindia M, Njiru W, Dimba E, Mutave R. Oral Squamous Cell Carcinoma: A 6-Month ClinicoHistopathologic Audit in a Kenyan Population. Open J Stomatol. 2014; 4:475-83.

26. Shenoi R, Devrukhkar V, Chaudhuri, Sharma BK, Sapre SB, Chikhale A. Demographic and clinical profile of oral squamous cell carcinoma patients: A retrospective study. Indian J Cancer. 2012;49:21-6

27. Scott SE, Grunfeld EA, McGurk M. The idiosyncratic relationship between diagnostic delay and stage of oral squamous cell carcinoma. Oral Oncol. 2005; 41:396403.

28. Morelatto RA, Herrera MC, Fernández EN, Corball AG, López de Blanc SA. Diagnostic delay of oral squamous cell carcinoma in two diagnosis centers in Córdoba Argentina. J Oral Pathol Med. 2007;36:405-8.

29. Syamsundar B, Nageswara RR, Faheem MK. Epidemiological and clinico pathological study of oral cancers in aTertiary care hospital. Int $\mathbf{J}$ Biol Med Res. 2012; 3:2376-2380.

30. Schmidt BL, Dierks EJ, Homer L, Potter B. Tobacco Smoking History and Presentation of Oral Squamous Cell Carcinoma. J Oral Maxillofac Surg. 2004; 62:10551058.

31. Sharma P, Saxena S, Aggarwal P. Trends in the epidemiology of oral squamous cell carcinoma in Western UP: An institutional study. Indian J Dent Res. 2010;21:316-9. 